\title{
Active Learning in Electronic Measurements and Instrumentation Course through hands-on
}

\author{
Nikita $\mathbf{P}^{1}$, Jyoti $\mathbf{P}^{2}$, Shraddha $\mathbf{B}^{3}$, Preeti $\mathbf{P}^{4}$, Raghavendra $\mathrm{S}^{5}$, Nalini C. Iyer ${ }^{6}$ \\ Department of Instrumentation Technology, \\ B.V. Bhommaraddi College of Engineering \& Technology, Hubli, Karnataka, India \\ ${ }^{1}$ nikhita_patil@bvb.edu, 2jyoti_patil@bvb.edu, $\quad{ }^{3}$ shraddha_h@bvb.edu, $\quad{ }^{4}$ preeti_pillai@bvb.edu, $\quad{ }^{5}$ raghu@bvb.edu, \\ ${ }^{6}$ nalinic@bvb.edu
}

\begin{abstract}
Electronic Measurements and Instrumentation involves with the measurement of various parameters related to the operation and use of electronic instruments. Measurements play a very important role in all engineering field. As a facilitator we have to strengthen the theoretical concepts by providing a platform for the students to analyze and design various instruments used for measurements. To improve the knowledge of measurements, analyzing and designing is the greatest challenge at the undergraduate level. This paper discusses implementation assignment as an activity introduced in this course to enhance the interest of the students. The purpose of introducing this activity was to correlate the theoretical concepts taught in the class with the hands-on experience. The details of the Implementation Assignment are also presented. The outcomes of the activity facilitates in terms of academic performance along with exploratory learning approach and presentation skills.
\end{abstract}

Keywords-Implementation Assignment, Measurements, Program Outcomes

\footnotetext{
Nikita $\mathbf{P}^{1}$

Department of Instrumentation Technology,

B.V. Bhommaraddi College of Engineering \& Technology, Hubli, Karnataka, India

${ }^{1}$ nikhita_patil@bvb.edu
}

\section{INTRODUCTION}

Electronics Engineering or Instrumentation Engineering is a discipline in engineering which utilizes active electrical components such as transistors, diodes, integrated circuits and passive electrical components such as resistor, capacitor to design the electrical circuit or a system. An Electronic Measurements and Instrumentation is a basic fundamental course which is studied at the third semester level which involves measurements of the electronic devices as well as to control and monitor various parameters. Controlling and monitoring plays a very important role in electronic devices. It is a course which is strongly characterized by the theory. With the rapid growth in modern electronics and instrumentation technology, the technologies involved in measurements have become rich and colorful. The traditional teaching methods are quite difficult to adapt to the modern instrumentation technology and it becomes hard to gain the attention of the students in this particular course [1].

The teaching contents of this course include bridges for measuring the passive components, characteristics of electronic instruments, voltmeters and ammeters etc. Verifying the concepts practically will be different from the theoretical concepts. In the existing teaching process most of the class hour is concentrated in the introducing of the basic measurement theory and the theory knowledge is deep and difficult for the students. Usually traditional measuring equipments (analog voltmeter, analog oscilloscope and analog signal generator) and traditional measuring approaches (such as bridges for measuring passive components) are used as examples in teaching process. Much time is depleted in analyzing the working principle, input/output characteristics of electronic equipments etc. In order to help the students to learn the subject effectively rather than only study it from an academic perspective an activity called as Implementation Assignment was designed. The concepts studied in the subject/laboratory can be better improved by applying the same to a real time application by the introduction of the Implementation assignment. The main objective in designing this activity was to correlate the theoretical concepts with practicals, since this is the basic course studied at the third semester level as per the curriculum. The concepts learnt in this course forms the 
basic foundation for the courses such as Linear Integrated Circuits and Process Instrumentation.

This activity was designed at third semester level in which students worked on the given problem statements. This activity helped the students to proceed with their course projects at higher semester levels. Activity started with assignment of different problem statements to each group of students. A prototype model was built by the students. In continuation with this, at fourth semester level students were able to implement real world applications.

The rest of the paper is organized as follows: Section II deals with the details of Methodology, Section III discusses about the Implementation details and assessment, effectiveness of the activity in Section IV, Section V discusses the experimental outcome. Finally the results and conclusion are discussed in Section VI.

\section{METHODOLOGY}

This section deals with the details of the Implementation Assignment Activity Completion.

Completion of the Implementation assignment involves the following various stages

- Group formation: Groups were formed comprising four students in each team and for each group team leader was identified. The roles and responsibilities of each student in a team were defined. It's the responsibility of the team leader to coordinate, plan and track the phases within the team.

- Assigning the problem statement \& Understanding: Once team formation was done each team was assigned with different kind of problem statements. Few teams were assigned with the passive components to be measured, few teams were assigned with studying the characteristics of the electronic equipments and few teams were assigned with extending the range of Voltmeter and Ammeter. The students have to make a thorough analysis on the given problem statement using the concepts taught in the class.

- Component Selection: Once the analysis on the problem statements is completed, Each team has to design the circuit to meet the requirements of the assigned problem statements. The components have to be selected as per the design.

- Implementation on the bread board and Printed Circuit Board: Each team has to rig up the connections on the breadboard, check the output on the breadboard. Once the output on the breadboard is verified the students have built the same circuit on the Printed Circuit board, and also built the prototype model and tested.

- Demonstration: Students have to effectively demonstrate the built prototype model. In addition to this each team has to prepare snaps/videos demonstrating the working prototype model. Finally students have to prepare the report on the work done.

\section{IMPLEMENTATION}

There were several reviews the students had to pass throughout the session of completion of the activity so that they were provided with the necessary guidance of the design process under realistic trade off conditions. Every ten days the progressive growth was observed through presentation by the team. Groups have to co-ordinate, organize, distribute the work among the team members and prepare the PPT showcasing the progress of their activity. This activity helped the students to correlate with the theoretical concepts and understand the course easily[2].

The following road map was developed to carry out the activity:

- Review 1: Literature survey phase where the students went through the given problem statements and made the analysis and approached with the design of the circuit diagram.

- Review 2: Bread board implementation where the students were reviewed for selecting the components as per the design of the circuit diagram. The students rigged up the connections as per the circuit diagram on the breadboard and validated the results.

- Review 3: PCB Design and validation phase where the students are reviewed for the PCB design of their bread board implementation and demonstration of their prototype of measurement system. Each review is associated with presentations so that the students develop in their presentation skills.

Following are the various problem statements on which the students worked and built the Prototype model of measurement system.

TABLE I. LISTING OF PROBLEM STATEMENTS

\begin{tabular}{|r|l|}
\hline Sl.NO & Problem Statements \\
\hline 1. & Wheatstone Bridge \\
\hline 2. & Wein's Bridge \\
\hline 3. & Schering Bridge \\
\hline 4. & Maxwell's Bridge \\
\hline 5. & $\begin{array}{l}\text { Static Characteristics Of } \\
\text { an equipment }\end{array}$ \\
\hline 6. & $\begin{array}{l}\text { Extending the range of } \\
\text { ammeter and voltmeter }\end{array}$ \\
\hline 7. & Multi-range Ammeter \\
\hline
\end{tabular}

Case Study:

Problem Statement: Conversion Of Galvanometer to a Multirange Ammeter

The Objective is to extend the range of a basic moving coil galvanometer to be used as an ammeter. The essential specifications of a basic moving coil galvanometer 
are internal resistance of the coil and current required for full scale deflection. By incorporating suitable shunt resistances, the galvanometer is converted into a multi-range ammeter.

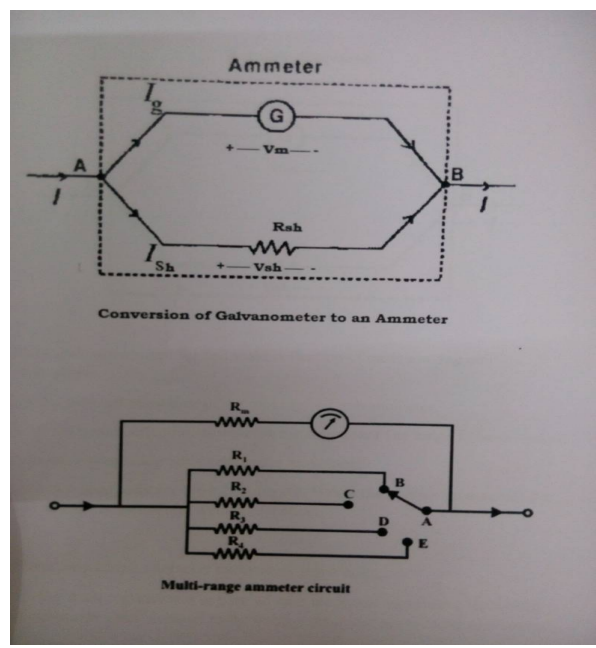

Fig.5. Design of the circuit

Ig is the current required for full scale deflection of basic moving coil galvanometer.

$\mathrm{Rg}$ is the internal resistance of the moving coil galvanometer.

I is the full scale deflection current of the ammeter(the range to be extended)

$\mathrm{Vm}$ is the voltage drop across the meter movement.

Rsh is the shunt resistance to be connected. Vsh is the voltage drop across the shunt and Ish is the current through the shunt.

Voltage drop across the meter movement is

$$
\mathrm{Vm}=\mathrm{IgRg}
$$
equation 1

Since the shunt resistance is in parallel with the meter movement, the voltage drop across the shunt is equal to the voltage drop across the meter movement.

$$
\mathrm{Vsh}=\mathrm{Vm}
$$
equation 2

The current through the shunt is equal to the total current minus the current through the meter movement.

$$
\mathrm{Ish}=\mathrm{I}-\mathrm{Ig}-
$$

Shunt resistance is determined by the equation

$$
\text { Rsh }=\text { Vsh/Ish-----------------equation } 4
$$

$\mathrm{Rsh}=(\mathrm{Ig} * \mathrm{Rg}) /(\mathrm{I}-\mathrm{Ig}) \Omega$-------------equation 5

Using the above equation the various values of shunt resistance can be calculated to form a multi-range ammeter. Observations:

- Internal resistance of galvanometer $\mathrm{Rg}=150 \Omega$

- Current required for full scale deflection of Galvanometer is $600 \mu \mathrm{A}$

- Rated current per division is $20 \mu \mathrm{A}$

For extending the range of galvanometer to $0-1 \mathrm{~mA}$

Using the above formula, the shunt resistance can be calculated as

$$
\begin{gathered}
\operatorname{Rsh}=[(600 \mu \mathrm{A}) *(150)] /[1 \mathrm{~mA}-600 \mu \mathrm{A})] \\
\operatorname{Rsh}=225 \Omega
\end{gathered}
$$

Similarly other Rsh values were calculated for the extension of the ranges and the prototype model was built.

Fig. 1.1 shows the samples of various prototype models built during the third semester as implementation assignment.

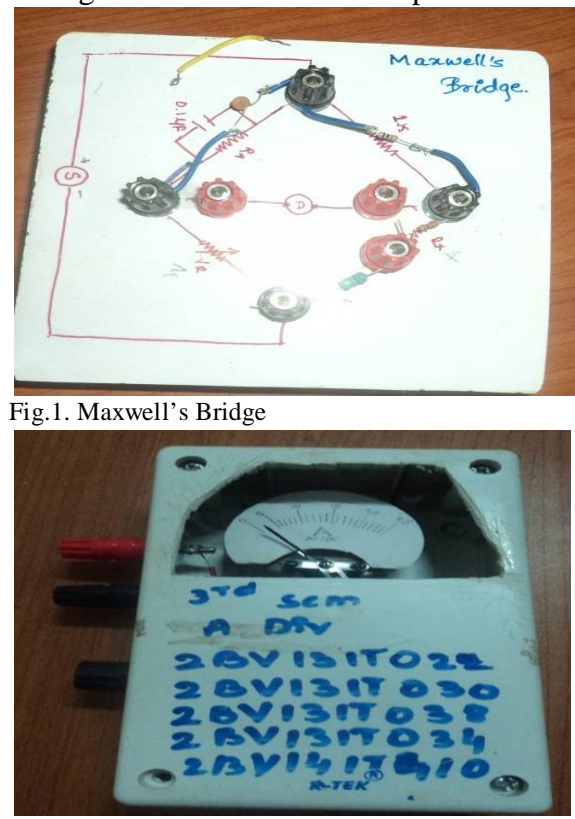

Fig.2. Extending the range of Ammeter

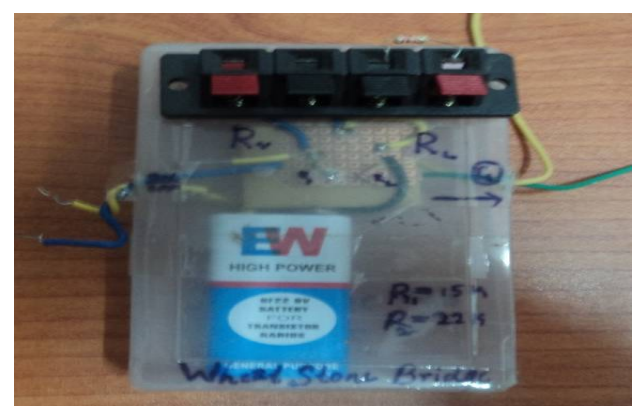

Fig.3. WheatStone Bridge

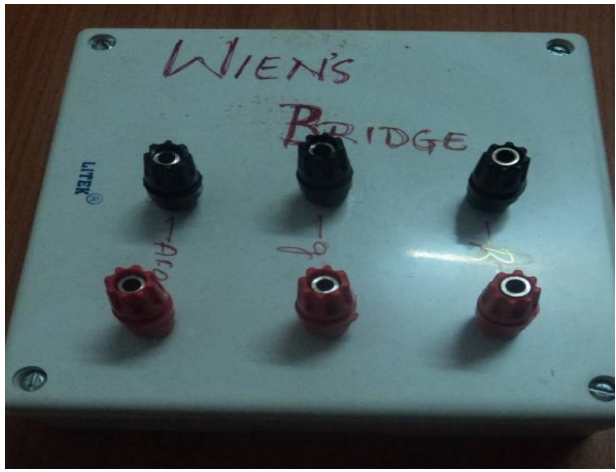

Fig.4. Wien's Bridge

\section{EFFECTIVENESS OF THE IMPLEMENTATION ASSIGNMENT}

A. Assessment

The effectiveness of the activity was assessed through student performance assessment and student feedback. The 
assessment rubrics for evaluating the performance of the students is as shown in the Table II.

TABLE II.ASSESSMENT CRITERIA

\begin{tabular}{|l|l|l|}
\hline Sl.NO & Assessment Criteria & Weightage \\
\hline 1 & Problem analysis & $20 \%$ \\
\hline 2 & Conceptual design & $20 \%$ \\
\hline 3 & $\begin{array}{l}\text { Implementation } \\
\text { BreadBoard } \\
\quad \begin{array}{l}\text { Printed Circuit } \\
\text { Board }\end{array}\end{array}$ & $\begin{array}{l}10 \% \\
30 \%\end{array}$ \\
\hline 4 & $\begin{array}{l}\text { Demonstration \& report } \\
\text { writing }\end{array}$ & $20 \%$ \\
\hline
\end{tabular}

B. Reflections Of the Implementation Assignment through feedback

Feedback Questionnaires for this activity is listed below:

\begin{tabular}{|l|l|}
\hline S.No & Questions \\
\hline 1. & $\begin{array}{l}\text { Did this activity enhance the purpose and } \\
\text { justification towards learning the concepts in this } \\
\text { course? }\end{array}$ \\
\hline 2. & $\begin{array}{l}\text { After this activity how do you rate the } \\
\text { understanding level of the course? }\end{array}$ \\
\hline 3. & $\begin{array}{l}\text { Did this activity motivated you have the self study } \\
\text { experience. }\end{array}$ \\
\hline 4. & $\begin{array}{l}\text { Did technique inspire you for collaborative } \\
\text { learning? }\end{array}$ \\
\hline 5. & Any other comments \\
\hline
\end{tabular}

The assessment based on the student feedback has been collected by each team and the detailed statistics of achievement of the activity is shown in the Fig.5.Question 1 relates to whether the students found this activity motivating enough to learn the concepts of this course. In response students found it very interesting to solve the problem statement and build a prototype of measurement system. Question 2 reflects on why the students are learning the particular concepts, where it is used and how the concept is applied, and in response $85 \%$ students agreed that this learning method helped them to correlate the theoretical concepts with practical's. After completion of this activity $89 \%$ students agreed that this technique helped them in developing self learning skills for solving a given problem and improving them in their presentation skills which is reflected in Question 3.For Question 4 \& 5, an attainment of $90 \%$ and $92 \%$ is observed to justify better understanding of the concept and enhancement in collaborative learning[3].

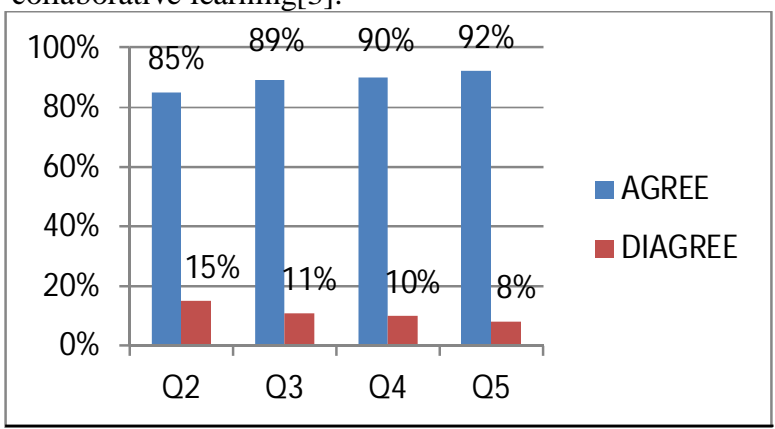

Fig.5. Feedback Questionnaire response

\section{Reflections Of the Implementation Assignment in Semester End Examination (SEE)}

The effectiveness of the activity has been reflected in the performance of students in Semester End Examination (SEE) where they were exposed to the higher levels of learning through Bloom's taxonomy. Comparison of the Semester End results of the academic year 2013-14 to the academic year 2014-15 for Electronic Measurements and Instrumentation course is been done and is observed that the percentage of the large classroom is increased as shown in the Fig.6.

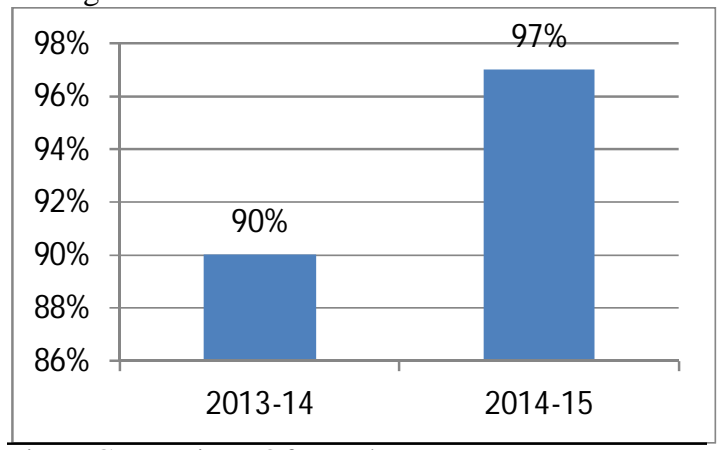

Fig.6. Comparison Of Results

\section{EXPERIMENTAL OUTCOMES AND DISCUSSIONS}

This activity as a learning technique is mapped to the learning outcomes a to $\mathrm{k}$ of Accreditation Board Of Engineering and Technology $(\mathrm{ABET})$ criteria as shown in the Table III.

TABLE III. ACTIVITY OUTCOMES MAPPING TO ABET PROGRAM OUTCOMES

\begin{tabular}{|c|c|c|}
\hline Steps & $\begin{array}{l}\text { Performance indicators } \\
\text { attaining the program } \\
\text { outcomes }\end{array}$ & $\begin{array}{l}\text { Program } \\
\text { Outcomes } \\
\text { a-k } \\
\text { criteria's } \\
\text { addressed }\end{array}$ \\
\hline Team work & $\begin{array}{l}\text { To collaboratively select the } \\
\text { best solution with } \\
\text { justification. }\end{array}$ & $\mathrm{d}$ \\
\hline \multirow{2}{*}{$\begin{array}{l}\text { Concept } \\
\text { Analysis }\end{array}$} & $\begin{array}{l}\text { Ability to apply theoretical } \\
\text { concepts. }\end{array}$ & $\mathrm{a}$ \\
\hline & $\begin{array}{l}\text { Ability to identify the } \\
\text { constraints, assumptions and } \\
\text { limitations. }\end{array}$ & $\mathrm{b}$ \\
\hline \multirow{2}{*}{$\begin{array}{l}\text { Embodiment } \\
\text { Design }\end{array}$} & Ability to develop a circuit. & $\mathrm{c}$ \\
\hline & $\begin{array}{l}\text { Ability to validate the } \\
\text { obtained results. }\end{array}$ & $\mathrm{i}$ \\
\hline $\begin{array}{l}\text { Presentation } \\
\text { Skills }\end{array}$ & 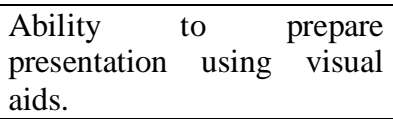 & $\mathrm{g}$ \\
\hline
\end{tabular}

The said course without presently adopted pedagogical techniques addresses only a and $\mathrm{g}$ in previous academic years while through this activity along with a and g,b,c,i were also addressed and attainment is as shown in Fig.7 


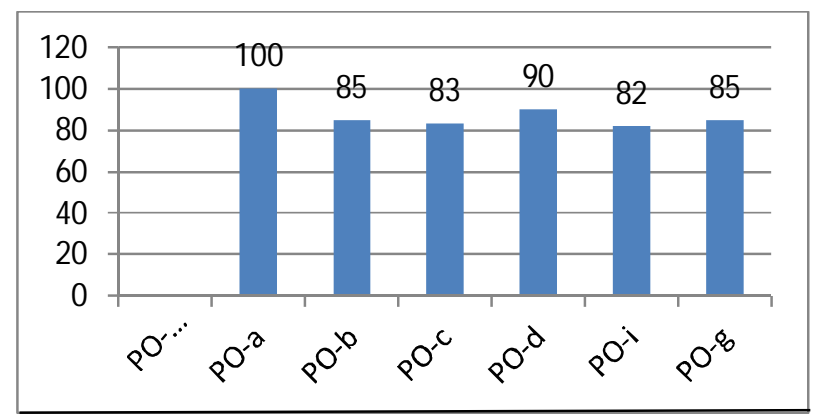

\section{CONCLUSION}

This paper presented the design, delivery and assessment of a Implementation assignment for the course Electronic Measurements and Instrumentation students at third semester. The techniques adopted for the assessment of the learning outcome have been listed and the results are presented. The most prominent positive outcome of the experiment is that over $90 \%$ of the students clearly indicated that this has given them a very good opportunity to evaluate, work on and improve their verbal as well as written communication skills apart from helping them in correlating the theoretical concepts with practical applications.

This is to observe that the innovative approach adopted has indeed significantly effective in improving the overall teaching learning process, encouraging the teachers and the students to extend the same to the relevant courses in the curricula program.

\section{REFERENCES}

[1] Nalini C Iyer, Kaushik M, 'An Experiment On Enhanced Learning through Field Exercise' Proceedings of IEEE MITE- 2013 International Conference on MOOC, Innovation and Technology in Education pg 53 2013

[2] Kaushik M, Preeti Pillai, Nalini C. Iyer, 'Prototype Implementation: An Effective Learning method in Process Automation' Journal of Engineering Education Transformations, Volume 28,No.2\&3, Oct 2014 \& Jan 2015

[3] B Shraddha,Raghavendra Shet, Nikita P 'Mind Mapping: An Useful Technique for Effective Learning in Large Classroom' Journal of Engineering Education Transformations

[4] Jennifer M. Case , Gregory Light, 'Emerging Methodologies in Engineering Education Research' Journal of Engineering Education January 2011, Vol. 100, No. 1, pp. 186-210

[4] Michael Prince, 'Does Active Learning Work? A Review of the Research', Journal of Engineering Education, July 2004, pp. 1-9.

[5] Nancy Van Note Chism,Elliot Douglas, Wayne J. Hilson, Jr, ‘ Qualitative Research Basics: A Guide for Engineering Educators', Rigorous Research in Engineering Education NSF DUE-0341127, 2008

[6] W.H. El Maraghy, 'Future Trends in Engineering Education and Research', Advances in Sustainable Manufacturing: Proceedings of the 8th Global Conference on Sustainable Manufacturing, pp. 11-16 